\title{
Carbon Neutral Village: The Australian Model
}

\author{
Joanne Stewart, Martin Anda*, David Goodfield, Goen Ho, Kuruvilla Mathew \\ Murdoch University, Perth, Western Australia \\ * Corresponding author. Tel: +61 89360 6123, E-mail: m.anda@murdoch.edu.au.
}

\begin{abstract}
This paper presents a model for carbon neutral land development as a mechanism to help drive innovation and emission reduction within the built environment sector. The carbon content model is comprised of the following:

- The greenhouse gas (GHG) embodied in the materials of the buildings and the infrastructure;

- The GHG emitted during the construction process with different approaches;

- The electrical power and natural gas used in the buildings for different building types;

- The transport fuels used in the construction and the on-going use by residents;

- The GHG produced in the full water cycle

- The GHG from the solid waste.

Understanding the interactions between the six elements of the model allows better decarbonisaton options to be developed. Two remote settlement cases are analysed. Firstly for a mine site camp, we introduce the "Smart Camp" digital control and monitoring concept . This includes sustainable village design, heating and cooling reduction, renewable energy, water use and reuse, and landscaping. Secondly, for the remote Aboriginal settlement, we address the need for sustainable livelihoods, including local food production and rangelands forestry and management.
\end{abstract}

Keywords: Carbon neutral, Life cycle analysis, Accreditation

\section{Introduction}

The built environment in Australia is currently responsible for around 20 percent of the nation's greenhouse gas emissions [1]). This is largely due to the energy consumed within buildings, as this energy predominantly comes from coal.

In Australia, carbon emission assessments for buildings are limited to operational energy. The Building Code of Australia (BCA) requires predictive calculations of operational energy use based on thermal performance modelling. The National Greenhouse and Energy Reporting (NGER) Act, 2007 requires actual emissions to be reported for facilities when the relevant energy or carbon emission thresholds are met. Analysing only operational emissions is similar to making an investment decision by solely examining the running costs of a building and ignoring the capital cost of development and construction.

If future construction is based on the need to reduce only the operational phase of the building, there is a real risk that further carbon emissions will be generated. from materials to increase operating efficiency. Hence, the proportion of emissions may be shifted from the operating phase to the 'before' and 'after-use' phases, without necessarily reducing overall emissions [2].

This paper is essentially a positioning paper that presents a model for carbon neutral land development as a mechanism to help drive innovation and emission reduction within this sector. The carbon content model is comprised of the following:

- $\quad$ The GHG embodied in the materials of the buildings and the infrastructure;

- $\quad$ The GHG emitted during the construction process with different approaches;

- $\quad$ The electrical power and natural gas used in the buildings for different building types; 
- $\quad$ The transport fuels used in the construction and the on-going use by residents;

- $\quad$ The GHG produced in the full water cycle

- $\quad$ The GHG from the solid waste.

It is considered that these elements comprise the major sources of carbon emissions, but it is important to understand how each element interacts with the others in order to reduce overall emissions. This more inclusive and holistic approach to village design is likely to result in reduced carbon emissions over its life. Two cases are analysed with the model: the remote mine site camp and the remote Aboriginal settlement.

\section{Methodology}

A literature review was undertaken to determine the methodology best suited to analyse the proposed carbon model of settlements. This was conducted in conjunction with a review of available tools to assess the six elements in the model, with project partners Curtin University. Data collection methods to populate the model will include interviews with service providers, surveys with communities and mine site operators, plus an active research method with a remote Aboriginal community. The data collection methods are still being refined.

\subsection{Carbon analysis method}

In order to fully determine the carbon emissions associated with a building or community, it is necessary to ensure the embodied and operating emissions are both measured in an appropriate calculation method. It is imperative that the method allows for comparability across a range of buildings and settlement types.

Carbon emission calculations can be conducted by a lifecycle analysis (LCA) method as they are for a wide range of products and services. LCA is supported by the International Energy Agency as a valuable methodology for examining the carbon of settlement development and the special assessment needs, such as adaptability of buildings and recyclability of materials can be incorporated [3]. The AS/NZS ISO standard 14040:1998 Environmental ManagementLife cycle assessment - principles and framework outlines the requirements and process for undertaking a lifecycle impact assessment. The standard states that the assessment is conducted for impacts throughout a product's life, or "cradle to grave", including raw material acquisition, through production, use and disposal [4].

Carbon Profiling [2] is a modification of LCA that can also be applied to settlements. This method develops a metric that includes the energy associated with land development, such as embodied energy in existing buildings on site and highlights the importance of the lifespan of linked components within the building system. This method proposes that end-of-life aspects not be incorporated as they are generally not decided at the time of construction but could be incorporated if the site is redeveloped in the future.

On this basis it was decided that a life cycle approach was appropriate and that consideration should also be given to any existing carbon on site and the life spans of linked components. End of life aspects would not be calculated, however the recyclability of materials will be included in considerations. Also the adaptability and transportability of structures that have a longer life span than the settlement requires, such as short term mine sites, would need to be considered where appropriate. 


\subsection{Review of software}

An extensive review of software was undertaken to evaluate their functionality to assess the six elements of the model [5]). The evaluation comprised a literature review to identify software designed to assess settlements, an evaluation of the software's ability to calculate carbon emissions related to each of the six elements and a pilot test of two to determine their appropriateness for mining and remote Indigenous settlements.

The review found that there are only a few software tools that provide the required functionality and none of them fully satisfied the six elements. However it was noted that recognition of life cycle analysis for settlement evaluation is growing and the USGBC has been investigating ways to incorporate an LCA module in its LEED evaluation tool (USGBC, 2006 [6]. The software chosen by the authors for the analysis of small-scale settlements was eTool, which satisfies four of the six element requirements: materials, construction process, operating energy and water systems. The software is currently being developed in Western Australia.

\subsection{Model design}

Based on the reviews above a model was developed to understand the interactions between the six key elements of settlements that generate carbon emissions. The model was then applied to the two remote settlement types: mine site camps and Indigenous communities.

The six elements of the carbon model are all interconnected and impact on each other. For example the choice of energy supply can impact on transport and waste energy. Remote settlements that are dependent on diesel generators for electricity require regular transport of diesel and services for maintenance of equipment and also have fuel drum waste to dispose of or recycle.

A schematic depiction of the key applications,is provided in Figure 1 below. 


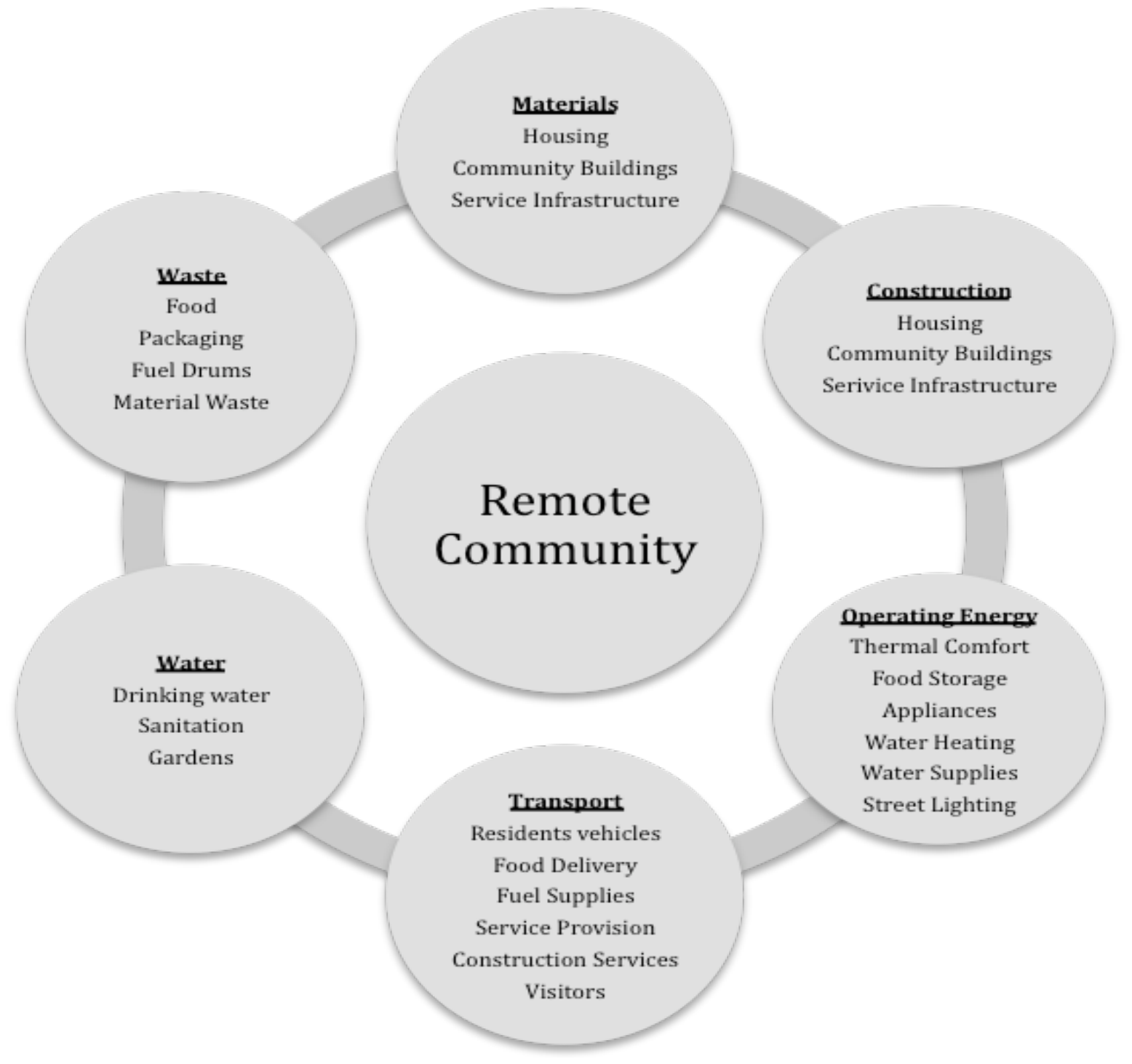

Figure 1 Carbon model with key applications of each element for both settlement types

\subsection{Application to Mining Camps}

Essentially a mine camp or village is a well defined organism and as such associated GHG emissions can be audited, monitored and controlled as a single entity. This research should, therefore, be able to provide a model for other types of remote community development where carbon reduction is an imperative.

The mining industry has a range of challenges to address in reducing its carbon emissions and providing a sustainable environment in its mine site camps and villages where they house their mining staff. Two known studies have been carried out where suggestions have been made for modifications to these camps and villages in order to reduce their carbon footprint $[7,8]$. The majority of emissions in the referenced case studies come from diesel fired generation of electricity to operate camp services. No published audited figures exist. Mining operations are generally set up and budgeted for a specific life. This lifespan will determine the longevity of the accommodation to service it during three main phases, namely: establishment, operation and finally the decommissioning and rehabilitation phase. This research intends to apply the tools and metrics in order to optimise, from a sustainability and low-carbon standpoint, the form and function of mine site accommodation. This way the 
mining companies are more likely to minimise their costs and maximise their return by creating the most appropriate type of accommodation to suit the prevailing circumstances.

Social behaviour clearly has its influence on carbon emissions research indicates that a change in behaviour will directly result in a reduction in these emissions. However, the task has been shown to be a none-too simple one [9]. This research intends to show that by changing the behaviour of the mine site employee, be they engineer or kitchen hand, that there will be considerable flow on effect in other areas of their lives, thus taking the carbon reduction strategy beyond that specific to the mine site accommodation itself [10].

Anecdotal evidence indicates the profligate use of energy in mine site accommodation is well known in the industry - for example air conditioners being left on in unoccupied buildings during a rostered-off period. Monitoring and control of operational energy is therefore a significant area where improvements could be made to make the camps and villages more energy efficient. In order to develop advanced monitoring and control solutions a collaboration between Furtwangen University, the Digital Ecosystems Business Intelligence Institute (DEBII) of Curtin University and this research has been formed. The interface between the digital world of control and monitoring systems is well established but this research will focus on the connection between them and the process of sustainable practice and education in a manner which to date is otherwise unexplored.

Stationary energy to service camp operations is generally generated using diesel as a fuel with high carbon polluting results. This research will also investigate the practical introduction of renewable energy systems to replace such fossil fuel consumption. These will include photovoltaic, solar thermal, geothermal, wind, and wave power (coastal only), and the appropriateness and sustainability of these technologies. From the mining company point of view a cost-benefit analysis will also need to be attached to the investigations.

\subsection{Application to Indigenous Communities}

In 2006 the Indigenous population of Australia was estimated to be 517,000 , which is $2.5 \%$ of the Australian population. Of these it is estimated that $24 \%$, approximately 124,000 , live in remote or very remote areas as classified by the Australian Standard Geographical Classification (ASGC) [11]. The communities in these areas range in size from small outstations to town-sized populations with various amenities [12].

While there is little published data on the carbon profiles of these communities, it is expected they are highly carbon intensive, despite their relatively low-income status. This is due to their general reliance on diesel-powered electricity generators, fossil-fuelled vehicles that need to travel vast distances and provision of public housing that is often inappropriate for the climate. They are also often dependent on external service providers and supply systems, all of which increase the transport requirements for goods and service delivery.

Energy use by households in these communities can vary widely from $3 \mathrm{kWh}$ to over $40 \mathrm{kWh}$ per day. This is due to a wide variation in the number of occupants per household, which is often high, and the appliances being used, particularly for air-conditioning and water heating. A community with 100 to 150 people would use between 500 to 750 litres of diesel per day to generate electricity, which emits approximately 1.3 to 2 tonnes of $\mathrm{CO}_{2} \mathrm{e}$ per day.

It is also reported that Indigenous communities in the north of Australia are likely to be highly impacted by the effects of climate change [13]. While decarbonising mainly aims to mitigate 
the effects of climate change, some of the proposed strategies to be employed can provide the twin benefit of adaptation and therefore help negate some impacts.

There are certainly reasons to maintain remote communities as opposed to relocating the residents into urban areas. These include improved health outcomes, such as in the community of Utopia ([11], and opportunities for income generation through natural resource management and carbon offset services [14].

Given the carbon profile in communities is highly influenced by their dependency on external factors such as energy, housing, food and general service supplies and lack of internal resources it is worth investigating the effect of transitioning communities to a more selfsufficient 'sustainable livelihood' model to address carbon emissions and also provide a suite of other benefits.

The Sustainable Livelihoods Framework, provided in Figure 2 below, has been used by international development agencies in attempts to address poverty in developing countries [15]. It also provides a framework within which to apply carbon management programs as livelihood strategies.

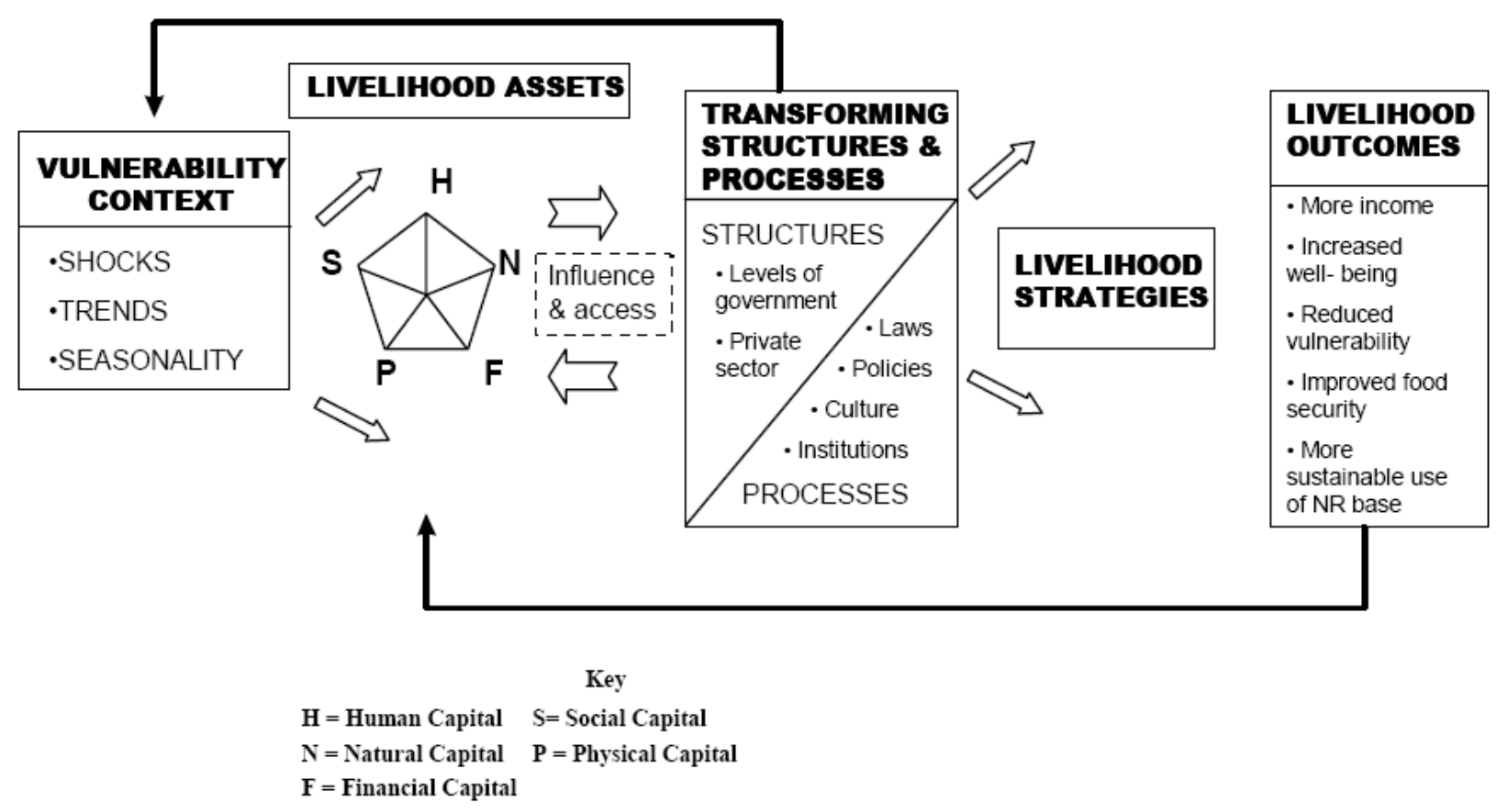

Figure 2 Sustainable Livelihoods Framework (source: Carney cited in [16])

By addressing the vulnerability factors and improving the five categories of assets (human, social, natural, physical and financial) a more sustainable community will develop. The connections to energy and carbon management are considerable. Firstly, using lifecycle analysis, the lifespan of a physical asset should be lengthened in order to maximise use of its embodied energy. The natural assets should be maintained to reduce energy use in relation to thermal comfort of buildings and food supplies and to generate carbon offsets, without upsetting the natural balance of other ecosystem services. Human and social assets are enhanced with skill development and network capability, which alleviate dependency on external goods and service provision, and therefore also transport needs. 


\section{Results}

For both remote settlement types there are clearly links between the six elements in the model and their impacts on carbon emissions. While the general links and possible solutions have been identified, further investigation and analysis is required to understand the exact connections and extent of impact.

As the model has not yet been applied results will not be available until further investigation of the carbon profiles and interconnections between elements have been examined and quantified.

\section{Discussion}

The model requires verification in the form of energy and emission quantities for each element and the key integration points. This will be conducted using the life cycle analysis method discussed. Identification and quantification of the key contributors to carbon emissions can then be completed. Proposed strategies, including the Sustainable Livelihoods framework and the digital monitoring system, need further research with application in pilot studies at remote settlements, which is currently being arranged. The success of these strategies will also be evaluated using a comparative life cycle analysis. Successful implementation methods that are suited to varying regional circumstances will need to be identified. Finally an accreditation process that certifies and incentivises transition to lowcarbon settlements will be investigated with research partners CUSP.

\section{Acknowledgements:}

Australian Research Council, Curtin University Sustainability Policy Institute (CUSP), Horizon Power and Parsons Brinckerhoff.

\section{References}

[1] Australian Sustainable Built Environment Council (ASBEC), The Second Plank Building a low carbon economy with energy efficient buildings. 2008, Australian Sustainable Built Environment Council (ASBEC).

[2] Sturgis, S. and G. Roberts, Redefining Zero: Carbon profiling as a solution to whole life carbon emission measurement in buildings. 2010, RICS: London.

[3] International Energy Agency Annex 31 Project, Life cycle assessment methods for buildings. 2004: Ottawa.

[4] Standards Australia, 14040:1998 Environmental Management - Life cycle assessment Principles and framework 1998, Standards Australia: Homebush.

[5] Beattie, C., et al., Carbon analysis of settlements and a review of appropriate tools. In press, 2010.

[6] Trusty, W., Integrating LCA into LEED: Working Group A (Goal and Scope) Interim Report \#1. 2006, US Green Building Council (USBGC).

[7] SKM, Improving the Sustainability of Mining Camps, a report by Sinclair Knight Merz. 2008.

[8] Anda, M. and D. Goodfield, Sustainable Village Design: A Study of Options. 2008. 
[9] Druckman, A. and T. Jackson, The Carbon Footprint of UK Households 1990 - 2004: A socio-economically dissagregated, quasi-multi regional input- output model. Ecological Economics, 2009. 68: p. 2066-77.

[10] Mulugetta, Y., T. Jackson, and D.v.d. Horst, Editorial. Energy Policy, 2010.

[11]SCRGSP (Steering Committee for the Review of Government Service Provision), Overcoming Indigenous Disadvantage: Key Indicators 2009, P. Commission, Editor. 2009, Productivity Commission: Canberra.

[12] Department of Indigenous Affairs (DIA), Facts at a Glance: Indigenous Demographics, D.o.I. Affairs, Editor. 2010, Government of Western Australia: Perth.

[13]Green, D., S. Jackson, and J. Morrison, Risks from Climate Change to Indigenous Communities in the Tropical North of Australia, D.o.C.C.a.E. Efficiency, Editor. 2009, Australian Government: Canberra.

[14]Alchin, M., E. Tierney, and C. Chilcott, Carbon Capture Project Final Report: An evaluation of the opportunity and risks of carbon offset based enterprises in the Kimberley-Pilbara region of Western Australia, D.o.A.a.F. WA, Editor. 2010, Department of Agriculture and Food WA: Perth.

[15] Fisher, S., Applying the Sustainable Livelihoods approach in the

[16]Australian Indigenous context, Centre for Appropriate Technology: Alice Springs.

[17] Measham, T., Y. Maru, and R. Murray-Prior, Outback Livelihoods: Defining and linking social and economic issues affecting the health and viability of Outback regions: Sample Discussion Paper. 2006, Tropical Savannas CRC and Desert Knowledge CRC: Darwin. 